\title{
Traumatic Open Anterior Hip Dislocation in an Adult Male: A Case Report
}

Anderson Freitas ${ }^{1}$, Vincenzo Giordano Neto ${ }^{2}$, Patrick F. Godinho ${ }^{3}$, Silvio L. Macedo ${ }^{4}$, Vinicius F. Ribeiro de Oliveira ${ }^{1}$, Gary Alan A. Montano ${ }^{1}$, Celio Silva ${ }^{1}$, Vanessa C. Bandeira ${ }^{1}$

1. Instituto De Pesquisa E Ensino-Ipe, Hospital Ortopedico E Medicina Especializada - Home, Brasilia, BRA 2. Orthopedics, Hospital Municipal Miguel Couto, RIo De Janeiro, BRA 3. Instituto De Pesquisa E Ensino-Ipe, Hospital Ortopedico E Medicina Especializada-Home, Brasilia, BRA 4. Instituto De Pesquisa E Ensino-Ipe, Hospital Ortopedico E Medicina Especializada - Home, Braslia, BRA

Corresponding author: Anderson Freitas, silviomneto31@gmail.com

\section{Abstract}

This case report describes the surgical treatment and one-year follow-up of an adult male patient, who was treated for a severe anterior open hip dislocation fracture with no sign of femoral head necrosis and maintaining a Harris Hip Score (HHS) of 93.

Categories: Physical Medicine \& Rehabilitation, Plastic Surgery, Orthopedics

Keywords: anterior hip dislocation, open dislocation of hip, trauma, femoral head necrosis

\section{Introduction}

The hip is a joint that has great stability, intrinsically due to its ball-and-socket shape and extrinsically due to its ligaments and strong muscles. A high-energy trauma is needed to cause the dislocation of the hip. Anterior hip dislocations are very uncommon and constitute $10 \%-15 \%$ of the traumatic displacements of this joint. However, when they do occur, they could be associated with brain, thoracic, and abdominal lesions as well as local lesions, such as neurological or severe vascular injuries, requiring immediate intervention. A reserved prognosis, due to the high rate of complications such as deep infections, femoral head necrosis, severe functional limitation, and arthrosis, is observed in several published case reports [1- 5]. The authors describe the follow-up of a fracture and a severe anterior dislocation of the hip in a young adult who surprisingly had a good outcome in the one-year follow-up, with a Harris Hip Score (HHS) of 93, no necrosis of the femoral head, and with only a slight degree of arthrosis.

\section{Case Presentation}

We present the case of a 28 -year-old male who suffered a high-energy motorcycle accident. At admission,

Received 04/03/2018

Review began 06/09/2018 Review ended 06/17/2018 Published 06/22/2018

๑) Copyright 2018

Freitas et al. This is an open access article distributed under the terms of the Creative Commons Attribution License CC-BY 3.0., which permits unrestricted use, distribution, and reproduction in any medium, provided the original author and source are credited. the patient was conscious, Glasgow coma scale (GCS) 15, hemodynamically stable, and presenting superficial excoriations on the trunk and lower limbs. However, there was a wound of approximately $20 \mathrm{~cm}$ on the lateral aspect of the right hip at the level of the greater trochanter, exposing the entire proximal end of the femur (Figure 1).

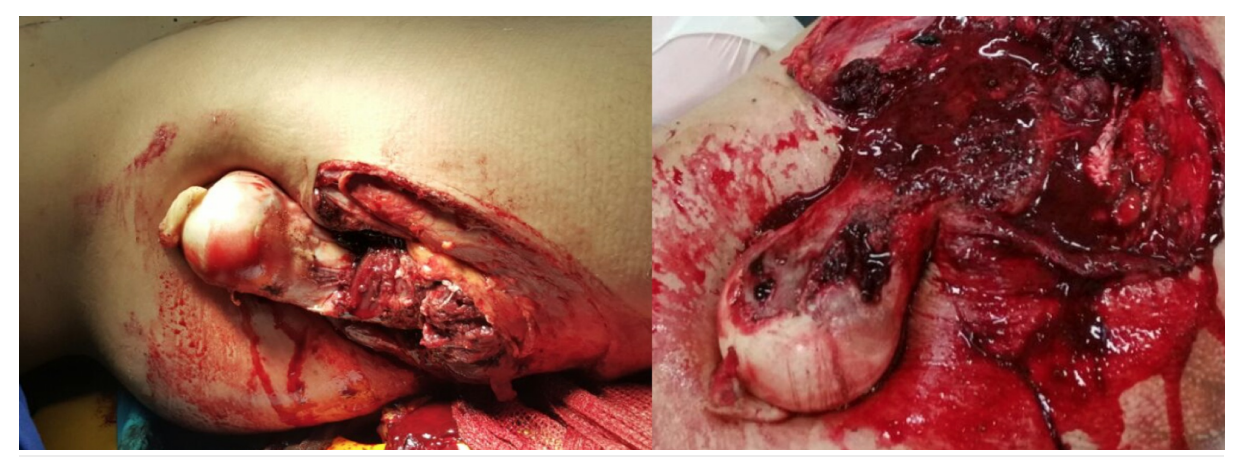
FIGURE 1: A photograph of the lesion in the right hip region, showing
the exposure of the entire proximal end of the femur

After a clinical evaluation and imaging tests that excluded cranial or abdominal disorders, we prioritized the neurovascular examination of the affected limb, which did not present complications, and the protection of the femoral head with the use of moistened gauze and saline solution. Radiographs in the anteroposterior view of the right hip showed a hip dislocation with a greater trochanter fracture (Figure 2). 


\section{Cureus}

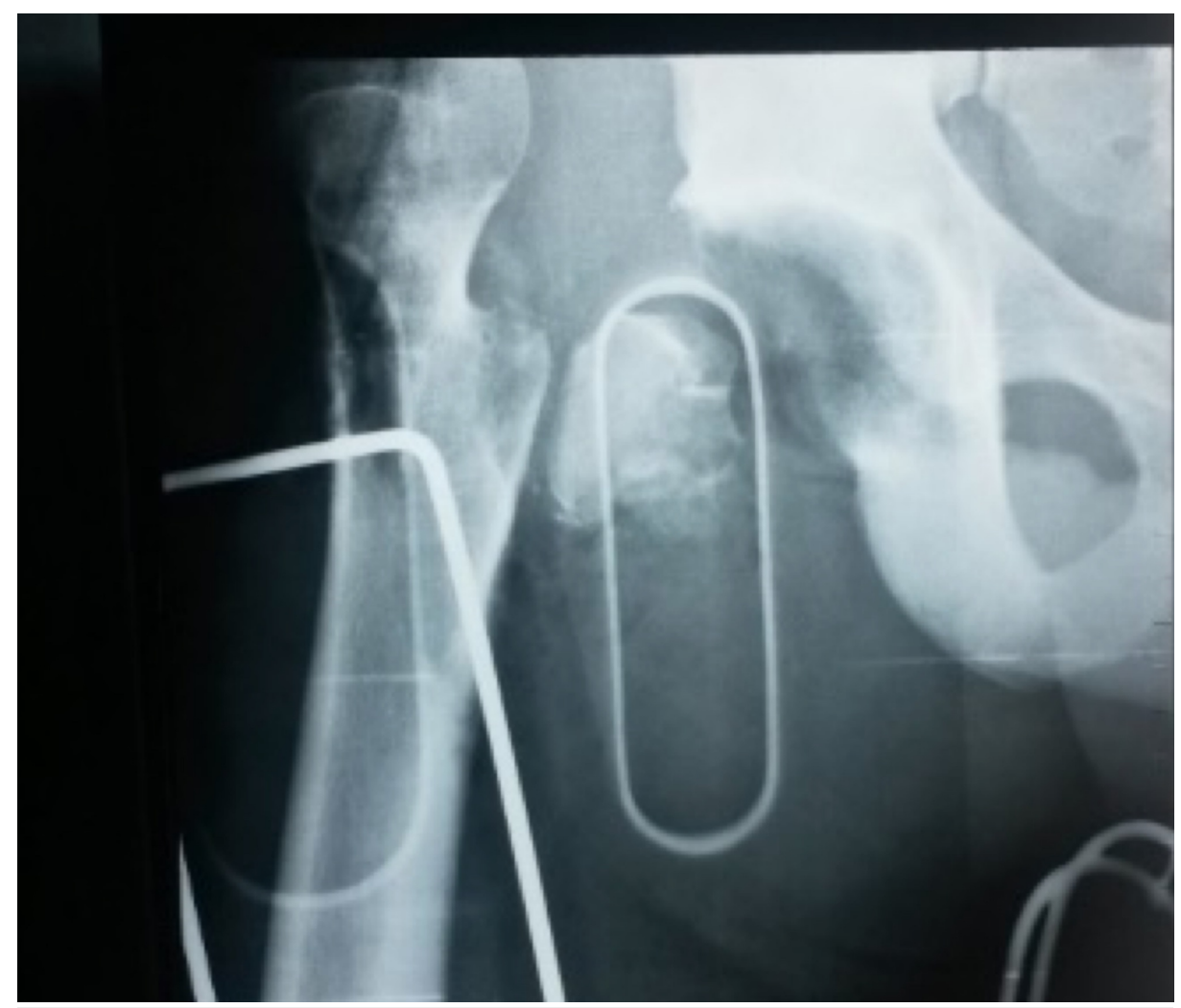

FIGURE 2: A radiograph of the right hip showing the dislocation with a fracture of the greater trochanter

An exhaustive irrigation of the acetabular cavity and the exposed femur was performed, using 10 liters of saline solution at $9 \%$ when the patient was in the surgical room. The procedure happened under sedation and spinal anesthesia. A large debridement of muscle, fascia, and bone tissues was required to remove all the devitalized tissue, considered viable only when active bleeding and the clean appearance of the open wound was observed through direct vision by the surgeons.

The fractured fragment of the greater trochanter was fixed with two $6.5 \mathrm{~mm}$ cancellous screws and washers at the proximal end of the femur (Figure 3). After a revision of the debridement sites and radioscopic control of the hip reduction and fixation, the wound was closed (Figure 4). 


\section{Cureus}

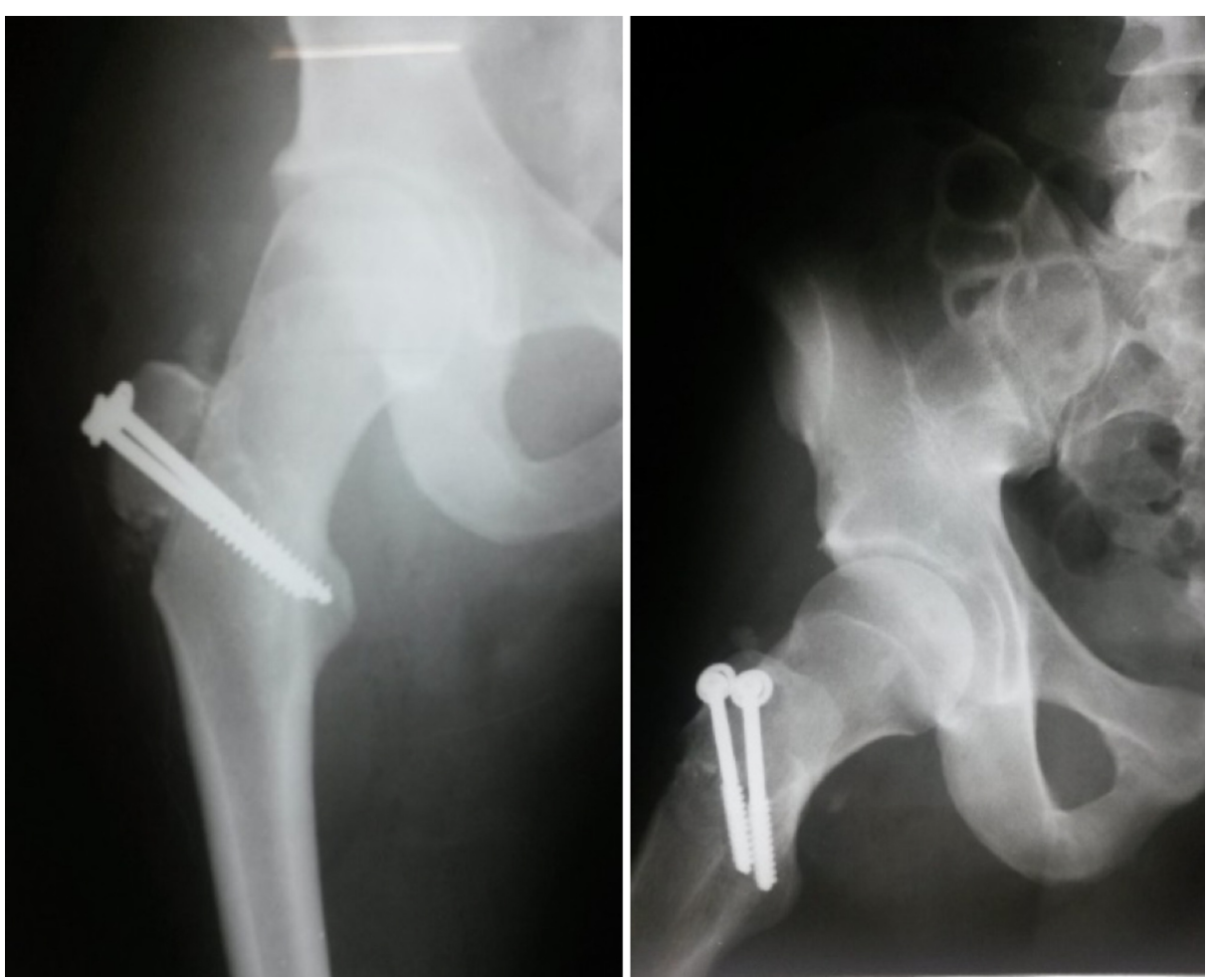

FIGURE 3: Image of a radiograph after surgery, showing hip reduction and the fixation of the greater trochanter 


\section{Cureus}

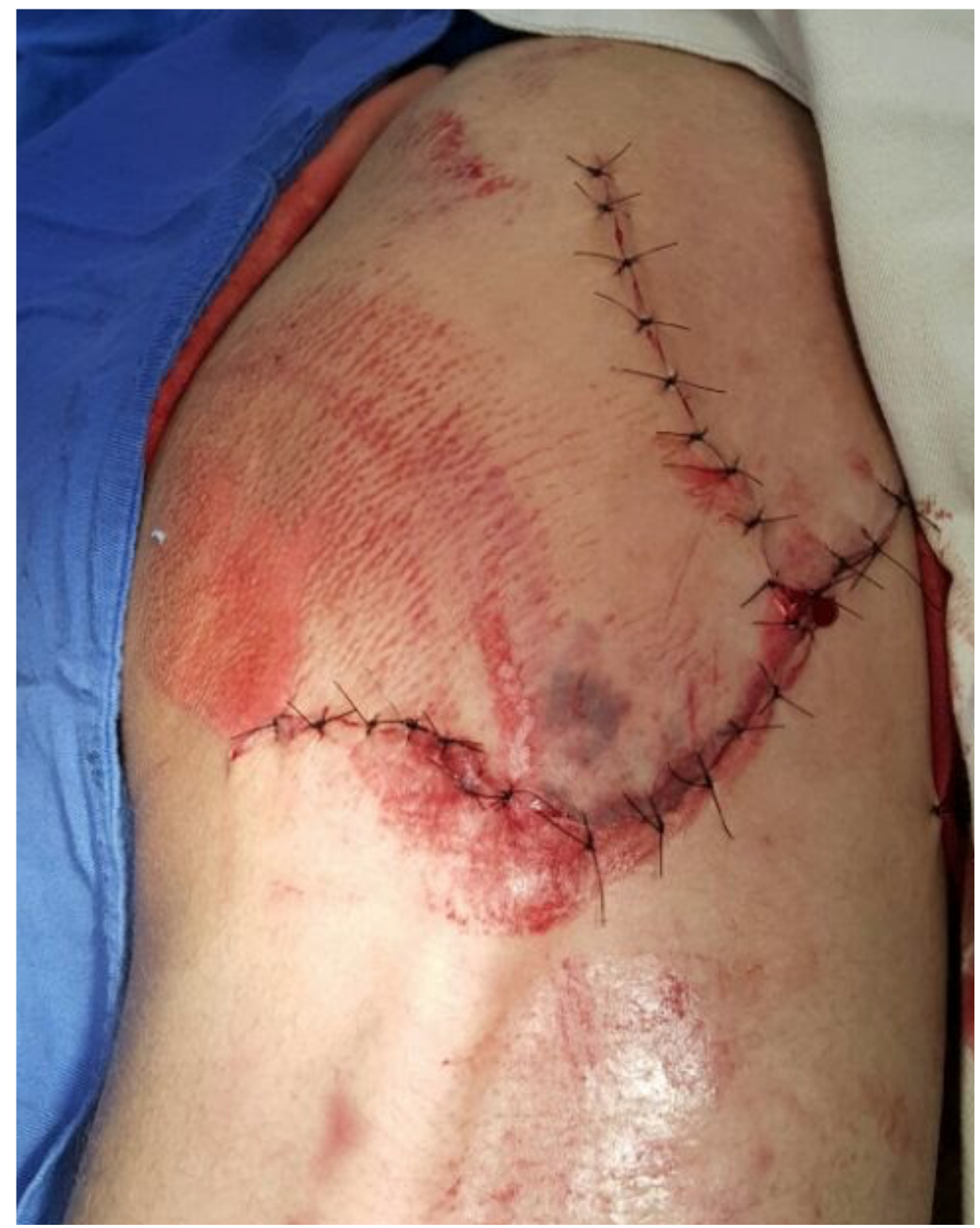

FIGURE 4: Picture of the lesion, showing the closure of the wound after surgery

After the first 48 hours of surgery, the wound was releasing a significant amount of secretion, bloody and serum like, and a strong odor was observed, with no laboratory exams indicating infection. At this time, a new surgical procedure (second look) with greater aggressiveness was obtained, removing all devitalized tissue and bad-in-appearance cutaneous cover, which was not necrotic but had an unhealthy appearance (Figure 5). A vacuum-assisted closure was used (Figure 6). 


\section{Cureus}

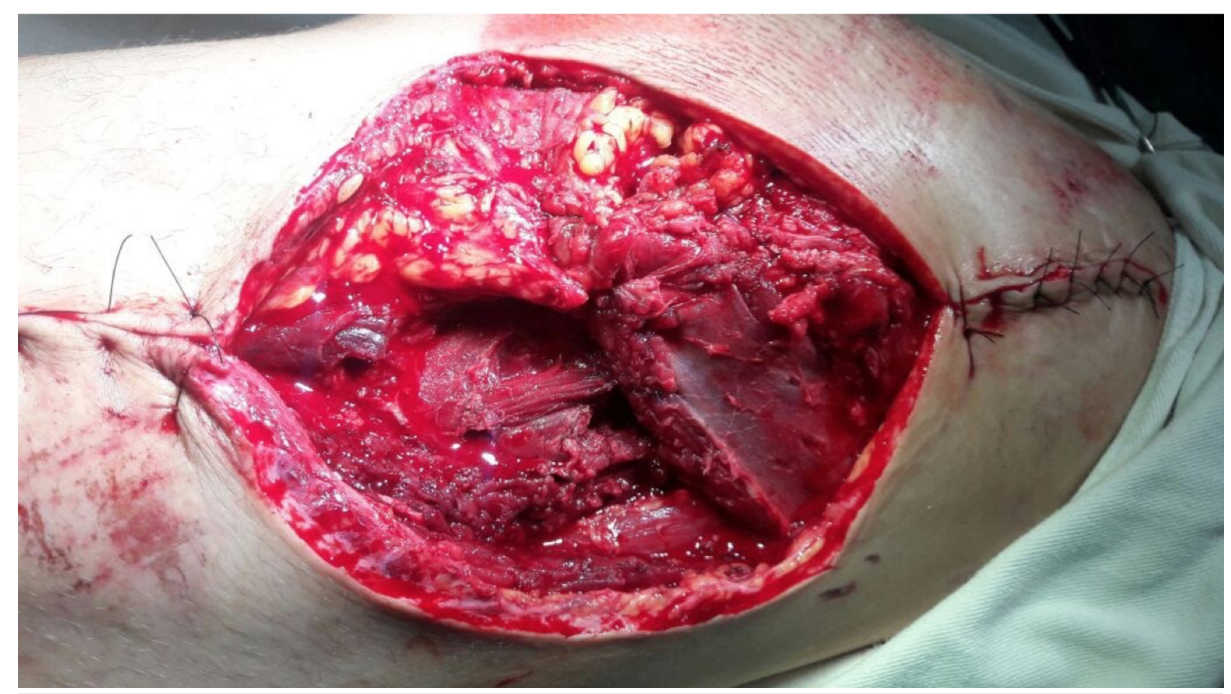

FIGURE 5: Picture of the wound after second-look surgery

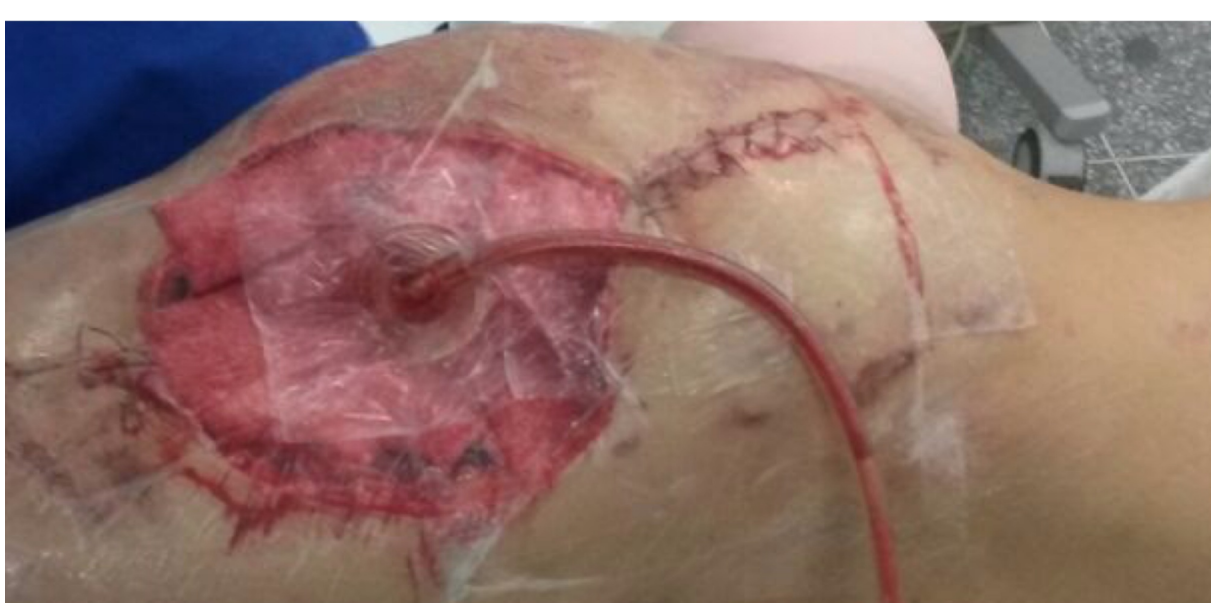

FIGURE 6: Picture of the vacuum-assisted closure of the wound

The vacuum-assisted closure was changed every week for four weeks until the appearance of granulation tissue at the surface of the surgical wound (Figure 7). During this period, the patient's laboratory exams showed a drop in the hemoglobin level, resulting in a $7.1 \mathrm{~g} / \mathrm{dl}$ result, which was corrected with a transfusion of $600 \mathrm{ml}$ of red blood cell (RBC) concentrate. As a rehabilitation procedure, we started daily physiotherapy with passive limb mobility and activity, within pain limits, with no load on the right hip. 


\section{Cureus}

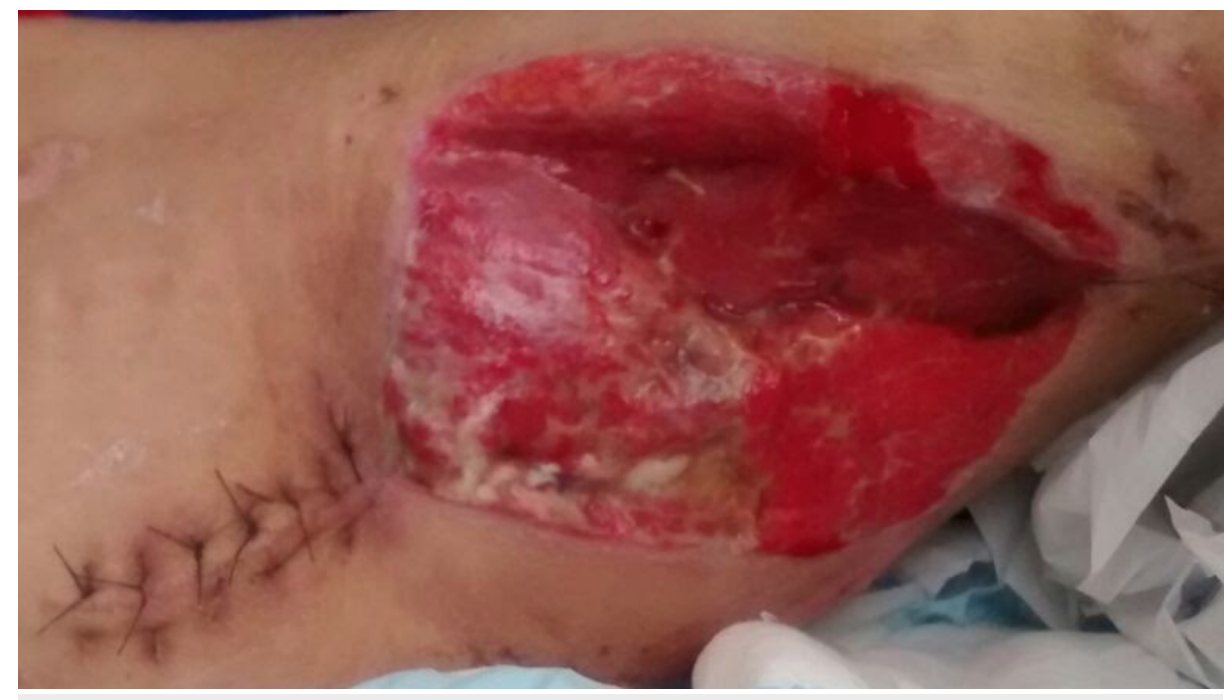

FIGURE 7: Picture of the wound after four weeks of vacuum-assisted closure

In the fifth week, a new surgical procedure was performed for skin grafting. It was performed with no major occurrences and implantation of the graft was successful. Shortly after the removal of the stitches from the graft surgery, in about eight weeks, partial weight bearing on the affected limb was initiated with the use of two crutches.

After a one-year follow-up, the patient had good mobility of the affected limb (Figure 8) without significant pain during mobilization and examination of the joint, with a Harris Hip Score of 93 points. The radiograph showed a decrease of the articular space in the right hip (Figure 9) but the magnetic resonance imaging (MRI) showed no necrosis of the femoral head. (Figure 10). He was able to ride a bicycle, run, and do squats.

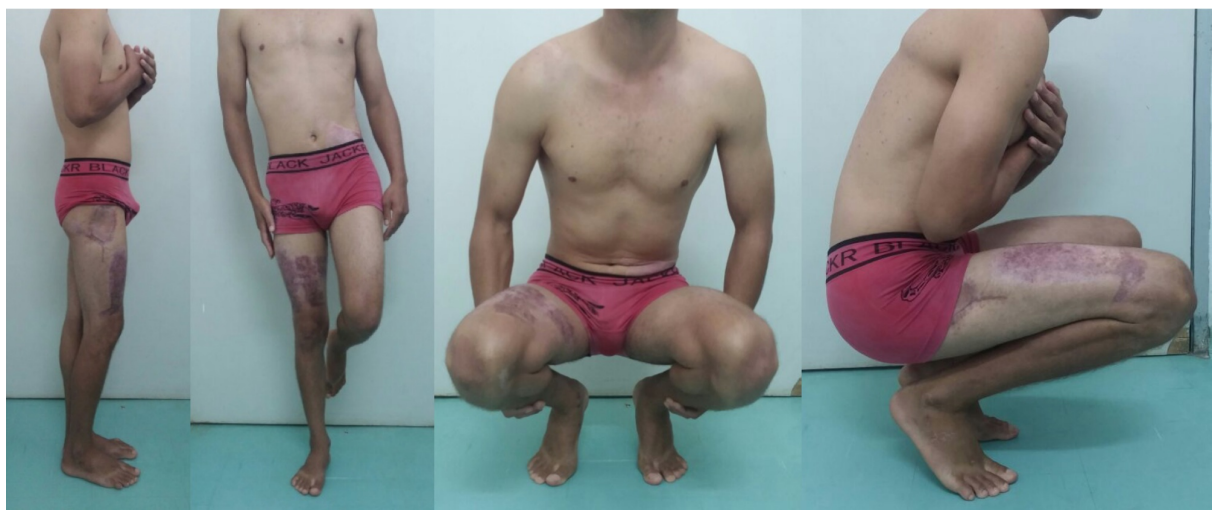

FIGURE 8: Pictures of the patient at the one-year follow-up 


\section{Cureus}

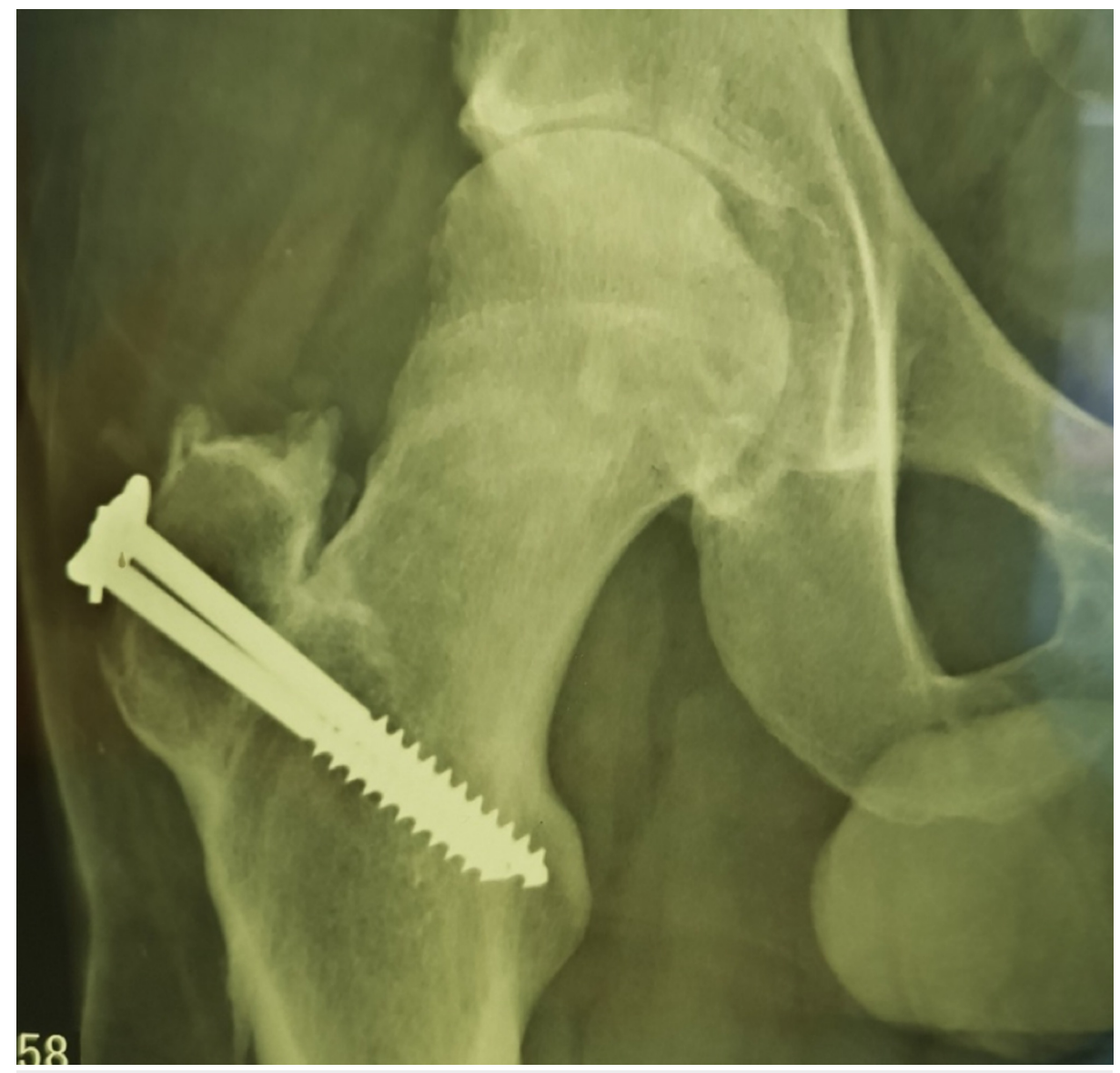

FIGURE 9: Radiograph showing the healing of the greater trochanter fracture and a narrowing of the hip joint space

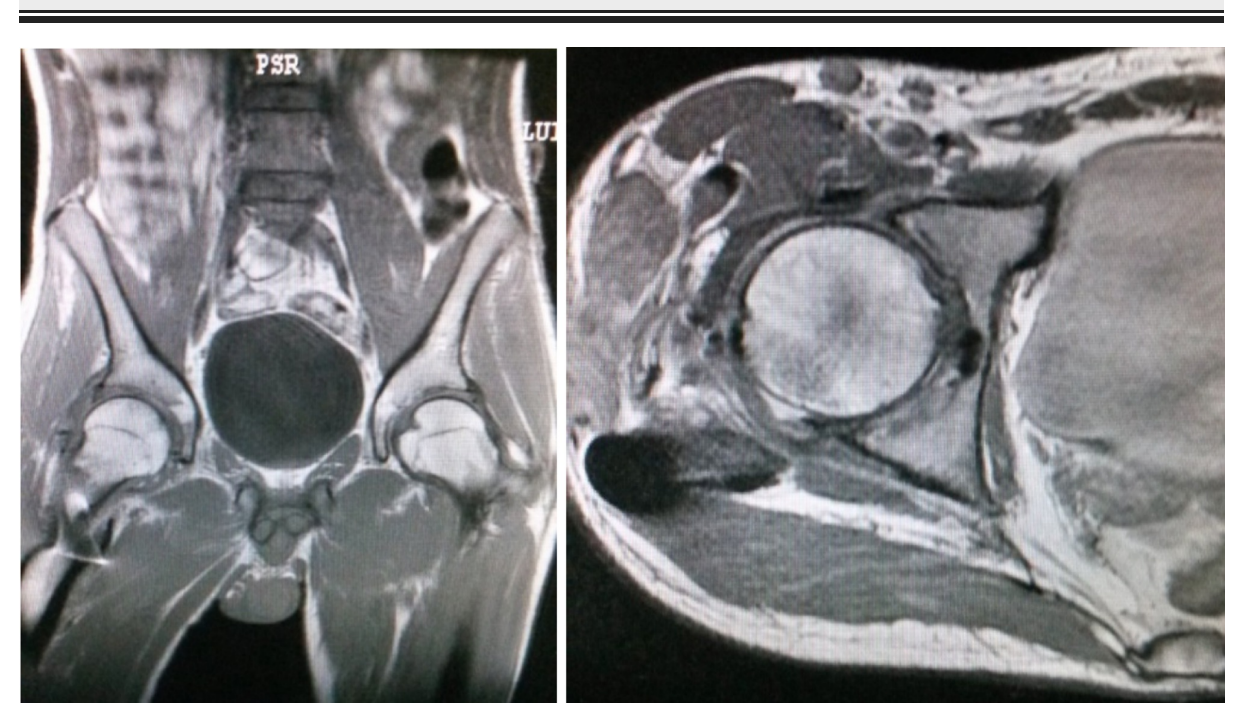

FIGURE 10: Pictures of the MRI, showing the reduction of the articular space and no necrosis of the femoral head

\section{Discussion}

An open anterior dislocation of the hip is a severe trauma with only a few reports described in the literature. Therefore, due to the rarity of the cases, especially in adult patients, there is a lack of treatment guidelines [1]. 
Immediate care with precautions taken during the reduction and subsequent debridement procedures, followed by the use of vacuum-assisted wound closure, may be a determinant of good outcomes by avoiding the occurrence of a deep infection [3].

Load restriction and early rehabilitation may have been a differential to avoid the complications of femoral head cartilage lesions, as greater pain limits the range of movement [4-5].

As seen earlier in literature, the fracture of the greater trochanter could be a protective factor for femoral head vascularization, especially if the fragment suffers a posterior deviation, sometimes being able to preserve the insertion of the external rotators. This may have been a reason for the maintenance of the medial circumflex artery close to the greater trochanter, allowing vascular restoration on the femoral head after reduction and fixation [6].

There is still no protocol or guideline for this type of fracture. Therefore, it is very clear that taking precautions during procedures such as reduction, cleaning, fixation, and rehabilitation is very important to achieve a better result and avoid or postpone the complications of this very serious fracture.

\section{Conclusions}

The very low number of cases like this in the literature leads us to affirm that there is no specific protocol to be followed. A functional limitation of the hip was imposed according to what was described previously in the literature. However, the absence of osteonecrosis, until this moment, showed a different result from all the case reports analyzed by the authors. The maintenance of vascularization from the femoral head made us believe that the association of a greater trochanter fracture with this pathology may be the reason for this outcome.

\section{Additional Information \\ Disclosures}

Human subjects: Consent was obtained by all participants in this study. Conflicts of interest: In compliance with the ICMJE uniform disclosure form, all authors declare the following: Payment/services info: All authors have declared that no financial support was received from any organization for the submitted work. Financial relationships: All authors have declared that they have no financial relationships at present or within the previous three years with any organizations that might have an interest in the submitted work. Other relationships: All authors have declared that there are no other relationships or activities that could appear to have influenced the submitted work.

\section{References}

1. Tornetta P 3rd: Hip Dislocations and Fractures of the Femoral Head . Michael S.H. Kain (ed): Williams and Wilkins, 2006. 1716-1752.

2. Erb RE, Steele JR, Nance Jr EP, et al.: Anterior dislocation of the hip: spectrum of plain film and CT findings Roentgenol. 1995, 165:1215-1219. 10.2214/ajr.165.5.7572506

3. Anderson Luiz de Oliveira AL, Machado EG: Open anterior dislocation of the hip in an adult: a case report and review of literature [Article in English, Portuguese]. Rev Bras Ortop. 2014, 49:94-97. 10.1016/j.rbo.2013.04.010

4. Şahin V, Karakaş ES, Aksu S, Atlihan D, Turk CY, Halici M: Traumatic dislocation and fracture-dislocation of the hip: a long-term follow-up study. J Trauma Acute Care Surg. 2003, 54:520-529. 10.1097/01.TA.0000020394.32496.52

5. Mehlman CT, Hubbard G, Crawford AH, Dennis RR, Wall EJ: Traumatic hip dislocation in children: longterm followup of 42 patients. Clin Orthop Relat Res. 2000, 376:68-79.

6. Freitas A, Macedo Neto SL: Apophysary fracture or avulsion of the greater trochanter . Acta Ortop Bras [online]. 2016, 24:164-166. 10.1590/1413-785220162403155803 